\title{
Conflicts of interest and industry professional relationships in psychiatric neurosurgery: a comparative literature review
}

\author{
Laura Y. Cabrera, PhD, ${ }^{1}$ Hayden M. K. Boyce, MD, ${ }^{2,3}$ Rachel McKenzie, ${ }^{4}$ and Robyn Bluhm, PhD ${ }^{4,5}$ \\ ${ }^{1}$ Center for Ethics and Humanities in the Life Sciences and Department of Translational Science \& Molecular Medicine, Michigan \\ State University, East Lansing; ${ }^{2}$ Spectrum Health Medical Group, Department of Neurosciences, Grand Rapids; ${ }^{3}$ College of \\ Human Medicine West Michigan, Michigan State University, Grand Rapids; "Lyman Briggs College, Michigan State University, \\ East Lansing; and 5 Department of Philosophy, Michigan State University, East Lansing, Michigan
}

OBJECTIVE The research required to establish that psychiatric treatments are effective often depends on collaboration between academic clinical researchers and industry. Some of the goals of clinical practice and those of commercial developers of psychiatric therapies overlap, such as developing safe and effective treatments. However, there might also be incompatible goals; physicians aim to provide the best care they can to their patients, whereas the medical industry ultimately aims to develop therapies that are commercially successful. In some cases, however, clinical research may be aiming both at improved patient care and commercial success. It is in these cases that a conflict of interest (COI) arises. The goal of this study was to identify differences and commonalities regarding COls between 2 kinds of somatic psychiatric interventions: pharmacological and neurosurgical.

METHODS The authors conducted a study focused on professional concerns regarding pharmacological and neurosurgical psychiatric interventions. They used medical and bioethics journal articles as an indicator of professionals' concerns and carried out a thematic content analysis of peer-reviewed articles published between 1960 and 2015, using PubMed and Google Scholar.

RESULTS One hundred thirty-seven relevant articles were identified, of which 86 papers focused primarily on psychopharmacology and 51 on neurosurgery. The intervention most discussed in the psychiatric neurosurgery data set was deep brain stimulation $(n=42)$. While there were no significant differences at the level of categories, pharmacological and neurosurgical interventions differ in the underlying themes discussed. Two issues widely discussed in the articles on pharmaceutical interventions, but largely neglected in the neurosurgery articles, were medical professional issues and industry involvement.

CONCLUSIONS COls are a neglected issue in the discussion of ethics concerns regarding medical devices in psychiatry. Yet as these interventions become more common, it is important to address them in part through learning from the discussion regarding COls in the pharmaceutical industry and by developing approaches to address those aspects of COls that are unique to the medical device industry.

https://thejns.org/doi/abs/10.3171/2018.4.FOCUS17399

KEYWORDS conflict of interest; industry; medical device; pharmaceuticals; psychiatry

$\mathrm{R}$ ESEARCH and development of psychiatric treatments often depends on collaboration between academic clinical researchers and industry. ${ }^{39,41,51}$ While the 2 parties share the aim of developing safe and effective treatments, they also have additional different aims, which can be in tension with each other. Physicians ultimately aim to provide the best care they can to their patients, whereas their industry partners ultimately aim to develop therapies that are commercially successful. ${ }^{17,35,48,52}$

In some cases, however, the physicians' aim may be both improved patient care and commercial success or the development of a scientific reputation. It is in these cases that conflicts of interest (COIs) arise. A COI occurs when professional judgment concerning a primary interest (such

ABBREVIATIONS COI $=$ conflict of interest; $\mathrm{DBS}=$ deep brain stimulation; $\mathrm{DTC}=$ direct-to-consumer; $\mathrm{OCD}=$ obsessive-compulsive disorder .

SUBMITTED June 7, 2017. ACCEPTED April 24, 2018.

INCLUDE WHEN CITING DOI: 10.3171/2018.4.FOCUS17399. 
as a patient's welfare or the validity of research) has the potential to be unduly influenced by a secondary interest (such as personal success or financial gain). ${ }^{54}$ This secondary interest need not be illegitimate; however, its influence on professional decision-making can be problematic.

To date, discussion of COIs in psychiatric treatment has been primarily focused on the pharmaceutical industry. In the past decade, however, there has been an increasing interest in research and clinical use of electronic devices in psychiatry, which raises the question of whether and how the use of medical devices may influence physicianindustry relationships.

\section{Methods}

We conducted a study comparing professional concerns regarding pharmacological and neurosurgical interventions via a systematic literature review of peer-reviewed articles published between 1960 and 2015 using PubMed and Google Scholar. The searches were based on 3 primary types of key terms: 1) intervention terms, 2) psychiatric disorder terms, and 3) ethics terms (Table 1). The study did not require IRB approval, as it did not include research with human subjects.

Articles were excluded if they were deemed to be irrelevant, were not full-length articles, or were unavailable through our university's library. We used thematic content analysis to identify and analyze patterns (themes) in the data. ${ }^{5}$ Articles were coded iteratively, with themes being developed as coding progressed, to identify major emergent themes. Two authors (L.Y.C. and R.B.) revised an initial set of codes and established a consensus list of codes. ${ }^{32}$ The unit of analysis was the individual article. We then applied the analytical framework to the full data set. ${ }^{5,46}$

Two members of the team coded the sources independently. Disagreements were addressed and settled by the entire team. Descriptive statistics were used to characterize the composition and properties of the samples, and the chi-square test was used to test for significant differences.

In this paper, we focus on medical professional issues and industry involvement, 2 themes widely discussed in

TABLE 1. Terms used in search

\begin{tabular}{|c|c|c|}
\hline Intervention Terms & Psychiatric Terms & $\begin{array}{l}\text { Ethics } \\
\text { Terms }\end{array}$ \\
\hline $\begin{array}{l}\text { Deep brain stimulation } \\
\text { Ablative surgery } \\
\text { Implantable devices } \\
\text { Vagal nerve stimulation } \\
\text { Optogenetics } \\
\text { Psychosurgery }\end{array}$ & $\begin{array}{l}\text { Psychiatric disorder } \\
\text { Obsessive compulsive disorder } \\
\text { Depression } \\
\text { Schizophrenia } \\
\text { Aggression } \\
\text { Anorexia } \\
\text { Anxiety } \\
\text { Addiction } \\
\text { Obesity } \\
\text { Dementia } \\
\text { Autism } \\
\text { Attention deficit hyperactivity } \\
\text { disorder }\end{array}$ & $\begin{array}{l}\text { Ethics } \\
\text { Ethical }\end{array}$ \\
\hline
\end{tabular}

articles on pharmaceutical interventions but largely neglected in neurosurgery articles. We coded for medical professional issues in any paper that included discussion of COI, doctor-patient relationship, and professional inertia. Industry-related issues included mention of industry or companies, marketing, lobbying for medical products, or COI (with explicit mention of industry involvement).

\section{Results}

One hundred thirty-seven relevant articles were identified, of which 86 papers focused primarily on psychopharmacology and 51 on neurosurgery. The technology most discussed in the psychiatric neurosurgery data set was deep brain stimulation (DBS; $n=42$ ). Advantages of the intervention - in particular, the reversibility and adjustability of DBS - were more frequently mentioned in the neurosurgery articles $(64.7 \%)$ than in the pharmacological ones $(7 \%)$. Neurosurgery articles also had more discussion of disadvantages (70.6\%) than did articles focusing on pharmaceutical interventions (37.2\%). The neurosurgery articles mentioned general risks associated with the intervention as well as more specific disadvantages relating to the invasiveness of the intervention and the fact that they involved direct modification of the brain (the last 2 disadvantages were not even present in the articles focusing on pharmacological interventions, which reflects differences in the interventions themselves). Other important differences were the amount of discussion in the neurosurgery articles regarding lessons from history as well as claims stating that these interventions should be used only as a last resort for cases in which the disorder proves resistant to more common treatment methods and concerns about the vulnerability of patients who may be desperate for treatment (Table 2).

The discussion of medical professional or industryrelated issues was more prevalent in the pharmaceutical data set than the neurosurgical one. One-third of articles $(34.88 \%)$ in the pharmaceutical data set discussed industry-related issues. In the neurosurgery data set, about onefifth $(17.6 \%)$ discussed these issues.

Some concerns, despite their distinct frequency, touch on similar issues. For example,

1) Issues of financial ties and improper inducements:

[...] free drug samples; free 'continuing education' courses in resort locations, often staffed by teachers associated with the company and sometimes featuring that company's products. $[\text { Pharmaceutical data set }]^{25}$

[...] corporate relationships, consulting fees, honoraria, research funding and intellectual property rights. [Neurosurgery data set ${ }^{39}$

\section{2) Issues of disclosure of COIs and public trust:}

Public trust in psychiatrists has been affected by serious accusations of conflicts of interest arising from failure to report such conflicts. [Pharmaceutical data set] ${ }^{51}$

The numerous conflicts of interest inherent within this research-especially when undisclosed-could act to undermine the research both by throwing doubt over the legitimacy of the study design and analysis as well as by risking a loss of public trust. [Neurosurgery data set] ${ }^{13}$ 
TABLE 2. Comparisons between psychopharmacology and neurosurgical intervention literature

\begin{tabular}{|c|c|c|c|}
\hline \multirow[b]{2}{*}{ Category \& Theme } & \multicolumn{2}{|c|}{$\%$ of Articles That Discussed the Relevant Theme } & \multirow[b]{2}{*}{ Value } \\
\hline & Psychopharmacology (86 coded articles) & Neurosurgical (51 coded articles) & \\
\hline Scientific \& technological issues & $75.58 \%(65)$ & $96.07 \%(49)$ & \\
\hline Scientific issues & $51.2 \%(44)$ & $66.7 \%(34)$ & \\
\hline Advantages & $7.0 \%(6)$ & $64.7 \%(33)$ & $\chi^{2}=52.39, p=0.0001^{*}$ \\
\hline Disadvantages & $37.2 \%(32)$ & $70.6 \%(36)$ & $\chi^{2}=14.268, p=0.0001^{*}$ \\
\hline Innovation & $20.9 \%(18)$ & $27.5 \%(14)$ & \\
\hline Clinical trial design & $51.2 \%(44)$ & $51 \%(26)$ & \\
\hline Social \& political issues & $90.69 \%(78)$ & $84.31 \%(43)$ & \\
\hline Medicalization & $27.9 \%(24)$ & $13.7 \%(7)$ & \\
\hline Social issues & $55.8 \%(48)$ & $52.9 \%(27)$ & \\
\hline Industry-related issues & $34.9 \%(30)$ & $17.6 \%(9)$ & $\chi^{2}=4.671, p=0.031 \dagger$ \\
\hline Media-related issues & $4.7 \%(4)$ & $23.5 \%(12)$ & \\
\hline Medical professional issues & $51.2 \%(44)$ & $31.4 \%(16)$ & $\chi^{2}=5.094, p=0.024 \dagger$ \\
\hline Political issues & $41.9 \%(36)$ & $64.7 \%(33)$ & $\chi^{2}=6.684, p=0.01 \dagger$ \\
\hline Patient issues & $74.42 \%(64)$ & $86.27 \%(44)$ & \\
\hline Issues of informed consent & $50 \%(43)$ & $76.5 \%(39)$ & $\chi^{2}=9.336, p=0.002^{*}$ \\
\hline Vulnerability & $29.1 \%(25)$ & $68 \%(34)$ & $\chi^{2}=19.509, p=0.0001^{*}$ \\
\hline Subgroups discussion & $54.7 \%(47)$ & $39.2 \%(20)$ & \\
\hline Therapeutic need & $11.6 \%(10)$ & $70.6 \%(36)$ & $\chi^{2}=49.901, p=0.0001^{*}$ \\
\hline Philosophical issues & $66.27 \%(57)$ & $82.35 \%(42)$ & \\
\hline
\end{tabular}

\section{3) Publication bias:}

Most of the negative randomized control trials concerned with psychotropic drugs do not get published. [Pharmaceutical data set $]^{14}$

[T]heir apparent exclusion from the data pool, as well as from Medtronic's report, is of some concern (i.e. it may have contained cautionary or unfavorable remarks). [Neurosurgery data set] ${ }^{13}$

4) Where to draw the line between research, treatment, and innovation:

The most difficult task for physician-investigators is recognizing that their agendas may not be the same as or in the best interest of their subject-patients. [Pharmaceutical data set] ${ }^{22}$

[...] the distinctions between research, innovation, and treatment become almost indistinguishable in procedures for serious conditions where no standard alternative therapy would provide a reasonable harm/benefit balance. [Neurosurgery data set $]^{21}$

In addition to quantitative differences, there were also important content-relevant differences between the data sets. For example, pharmaceutical articles approached issues such as medical education and industry, which are seldom raised in the context of the neurosurgery data set: "Researchers who have their research or teaching activities funded by pharmaceutical companies may also experience [a] moral dilemma." 53 Another difference is related to issues of studies sponsored by industry. In the case of pharmaceuticals: "Studies sponsored by pharmaceutical companies are more likely to have outcomes favorable to the sponsor. Industry sponsorship also results in restrictions on publication and data sharing, and in selective reporting." ${ }^{14}$ In the case of neurosurgical devices, investigators often rely on the medical device company donating or making available the equipment for the surgery: "Medtronic also often makes a practice of donating the equipment for the surgery used in highly experimental and investigational uses."13

Issues of intellectual property, startups, and the BayhDole Act, while relevant for both types of interventions, were found only in the neurosurgery data set: "[The BayhDole Act] is especially significant for DBS research, which revolves around access to costly proprietary devices." ${ }^{13}$ Marketing, including direct-to-consumer (DTC) advertising, was almost uniquely mentioned in the pharmaceutical data set: "Private companies have set campaigns to shape a favorable climate of opinion for their drugs." 15

There were also differences regarding medical professional issues. In the pharmaceutical data set half of all articles $(51.2 \%)$ raised medical professional issues, whereas only one-third of neurosurgery articles touched on the issue $(31.4 \%)$. However, the pharmaceutical data set focused mostly on medical professional issues involving psychiatrists, who are more likely to prescribe these medications, whereas the neurosurgery set focused on issues involving neurosurgeons.

\section{Discussion}

Our results suggest that the potential ethical implications of industry-professional relationships, including 
TABLE 3. Comparison of topics in the pharmacological and neurosurgical psychiatric interventions discussion regarding COls

\begin{tabular}{|c|c|c|}
\hline & Pharmaceuticals & Medical Devices \\
\hline $\begin{array}{l}\text { Financial ties \& } \\
\text { improper induce- } \\
\text { ments }\end{array}$ & $\begin{array}{l}\text { - Financial ties with industry: researchers, clinicians, advisory } \\
\text { committee members. } 7,15,26,29,42,50,51,53 \\
\text { - Improper inducements, including free drug samples, free } \\
\text { continuing education courses in resort locations, expensive } \\
\text { dinners. } 7,25 \\
\text { - Financial incentives for "successful recruitment and enroll- } \\
\text { ment." } 44 \\
\text { - "Receipt of gifts adversely affects physicians' prescribing } \\
\text { behavior." } 42\end{array}$ & $\begin{array}{l}\text { - Conflicting roles in industry-sponsored research (e.g., } \\
\text { company advisor, consultant, honorarium, and/or } \\
\text { shared patents).13,17,48 } \\
\text { - Improper inducements, including study contracts, profes- } \\
\text { sional advancement, consultant fees. }{ }^{13,17}\end{array}$ \\
\hline $\begin{array}{l}\text { Medical education \& } \\
\text { industry }\end{array}$ & $\begin{array}{l}\text { - Research or teaching activities funded by pharmaceutical } \\
\text { companies. }{ }^{15,26,53} \\
\text { - Marketing biases in therapeutic information. }{ }^{42,51}\end{array}$ & $\begin{array}{l}\text { - "The dissemination of miracle stories presents an educa- } \\
\text { tional vulnerability." }{ }^{21}\end{array}$ \\
\hline $\begin{array}{l}\text { Editorial practices \& } \\
\quad \text { disclosure }\end{array}$ & $\begin{array}{l}\text { - Ghost writing, publications that are "infomercials." 7,14,25,34 } \\
\text { - Ineffectiveness of disclosure policies. }{ }^{40} \\
\text { - Undermines public trust, "not simply in a particular paper or jour- } \\
\text { nal, but in the integrity of the scientific enterprise as a whole." } \\
\text { - Public trust in psychiatrists has been affected from failure to } \\
\text { report conflicts of interests. }{ }^{.1}\end{array}$ & $\begin{array}{l}\text { - "Investigators should be transparent with disclosures of } \\
\text { financial conflicts of interests" in all informed consent } \\
\text { discussions. }{ }^{39} \\
\text { - Questionable disclosure practices. }{ }^{13} \\
\text { - "Undermine the research both by throwing doubt over } \\
\text { the legitimacy of the study design and analysis as well } \\
\text { as by risking a loss of public trust." }{ }^{3,39}\end{array}$ \\
\hline Publication bias & $\begin{array}{l}\text { - Studies sponsored by pharmaceutical companies are more likely } \\
\text { to have outcomes favorable to the sponsors. }{ }^{14,27,51} \\
\text { - Restrictions on publication and data sharing. } .^{6,26,40} \\
\text { - Methods for detecting and correcting for publication bias have } \\
\text { limitations. }{ }^{16}\end{array}$ & $\begin{array}{l}\text { - Exclusion from the data pool and industry report. }{ }^{13} \\
\text { - Industry personnel involved in targeting and analysis. }{ }^{13}\end{array}$ \\
\hline Industry-funded trials & $\begin{array}{l}\text { • Evidence bias. }{ }^{14,16,34} \\
\text { - "Pharmaceutical industry does not generally fund long-term } \\
\text { studies of medications." }{ }^{24}\end{array}$ & $\begin{array}{l}\text { - Disincentive to formally study surgical procedures that } \\
\text { are not device related. }{ }^{21} \\
\text { - Lack of competitors in the DBS market. } \\
\text { - Industry donation of the equipment for the surgery used } \\
\text { in highly experimental and investigational uses. }{ }^{13} \\
\text { - "Market based approach to inquiry." }{ }^{19}\end{array}$ \\
\hline $\begin{array}{l}\text { Bayh-Dole Act, intel- } \\
\text { lectual property, \& } \\
\text { start-ups }\end{array}$ & & $\begin{array}{l}\text { - The revision of the Bayh-Dole Act to suspend the trans- } \\
\text { fer or sale of intellectual property rights until early stage } \\
\text { research (Phase I trials) is completed. }{ }^{13,17} \\
\text { - Intellectual property information related to the FDA's } \\
\text { approval is not available. }{ }^{13} \\
\text { - "Granting a humanitarian device exemption [...] could } \\
\text { be a consequence of inadequate enforcement of exist- } \\
\text { ing FDA rules or corporate economic motivations to } \\
\text { broaden the applications of existing technologies." }{ }^{17}\end{array}$ \\
\hline $\begin{array}{l}\text { Marketing, advertise- } \\
\text { ment, media }\end{array}$ & $\begin{array}{l}\text { - The role of advertising. }{ }^{15,16,34,49} \\
\text { - Drug company promotion and propaganda. }{ }^{6} \\
\text { - "The growing role of advertising agencies in the business of } \\
\text { conducting clinical trials of pharmaceuticals." } \\
\text { - DTC advertising. }{ }^{26,51}\end{array}$ & $\begin{array}{l}\text { - The role of the media in communicating developments in } \\
\text { this area. }{ }^{21}\end{array}$ \\
\hline $\begin{array}{l}\text { Research, innovation } \\
\quad \& \text { treatment }\end{array}$ & $\begin{array}{l}\text { - Treating clinician versus research clinician. }{ }^{14,22,42,55} \\
\text { - "Abuse of the trust implicit in the relationship between patient } \\
\text { and doctor." }{ }^{44} \\
\text { - "Doctors themselves seldom have much direct knowledge about } \\
\text { the research used to justify the use of psychiatric drugs." }{ }^{6}\end{array}$ & $\begin{array}{l}\text { "The distinctions between research, innovation, and } \\
\text { treatment become almost indistinguishable" in these } \\
\text { types of procedures. }{ }^{21} \\
\text { - Ambition and desire for fame. }{ }^{18} \\
\text { - Investigational new device. } .^{17}\end{array}$ \\
\hline $\begin{array}{l}\text { Recommendations \& } \\
\quad \text { guidelines }\end{array}$ & $\begin{array}{l}\text {-While the FDA requires IRB approval of study advertisements, } \\
\text { there is no such requirement in the Common Rule."44 } \\
\text { "The new standards do not have the force of law." }\end{array}$ & $\begin{array}{l}\text { - Disclosure of COI to regulatory bodies and potential } \\
\text { enrollees. } 13,18,39,48 \\
\text { - "There are currently no guidelines regulating innovative } \\
\text { surgery;" "there are limits to relying on self-enforce- } \\
\text { ment practices of corporations." }{ }^{13}\end{array}$ \\
\hline
\end{tabular}


COIs, have been largely neglected in the discussion of ethics issues raised by psychiatric neurosurgery. This is particularly true for neurosurgery involving implantable devices (such as DBS) or requiring special devices (such as radiosurgery). Our results also underscore the similarities and differences in the way in which different concerns manifest with regard to the 2 types of treatment. Here, we draw on both the existing bioethics literature and the findings of our comparative analysis to discuss these differences (Table 3).

Erickson-Davis ${ }^{13}$ addressed the lack of discussion of COIs in the bioethical analysis of DBS for obsessive-compulsive disorder (OCD), attributing it to a tendency among bioethicists to focus on clinical decision-making rather than on the broader context within which these decisions are made. Our results suggest that this is not the complete story, as there is a robust discussion of COIs and industryrelated concerns in the literature on pharmacological interventions in psychiatry. $1,2,7-10,14,25,28,30,34,39,58$ Several factors provide at least a partial explanation for the relative lack of discussion of COIs in psychiatry and medical devices.

\section{DBS Is New, Pharmaceuticals Are Not}

First, DBS is both a relatively new and a relatively rare treatment in psychiatry. Psychiatric neurosurgery almost disappeared from the medical arsenal in the 1970s because of reactions to the use of lobotomy, while at the same time the first psychopharmacological agents started to be used. ${ }^{56}$ This created a gap of several years in which the pharmaceutical industry dominated the psychiatric therapeutic arena. It was only after 1999 that psychiatric neurosurgery saw a revival..$^{33,38,37}$ Moreover, unlike DBS, the early days of psychiatric neurosurgery did not involve the medical device industry, which has proprietary interests in both the equipment and the techniques now being used. ${ }^{45}$

In contrast to DBS, there is a long history of the use of pharmaceuticals in psychiatry and of public discussion of scandals related to pharmaceuticals (e.g., the use of antidepressants in children). There is also broad awareness of pharmaceutical industry influence on medical practice and medical education. ${ }^{23,26,43,51,57}$ This includes the use of opinion leaders in specific areas of medicine to promote the company's products, as well as gifts ranging from mundane office supplies to luxurious weekends as medical "education" events.

The impact of the pharmaceutical industry in attracting the attention of both bioethicists and the public regarding COIs can also explain why in some of the neurosurgery articles, the COIs mentioned were more directed toward the pharmaceutical industry than the medical device industry. The last-resort nature of these procedures, their extensive workup, and the fact that they have not been proven effective might also be reasons for why COIs may not have been as broadly discussed as they are in the case of pharmaceuticals.

\section{Restriction to Treatment-Resistant Disorders: Less Room for Overuse of Invasive Medical Devices}

Second, the very specific use of psychiatric neurosur- gery interventions (severe, treatment-refractory psychiatric disorders) and their experimental nature may mean there is less room for overuse of medical devices. This may, however, be an overly optimistic view, as 2 of the neurosurgery papers discussing COIs extensively were connected to the humanitarian device exemption granted to Medtronic for one of its neurostimulators for treatmentrefractory OCD. Both Fins et al. ${ }^{17}$ and Erickson-Davis ${ }^{13}$ suggested that DBS will be increasingly used as companies attempt to increase their market share. This increase may come not only by characterizing more patients as good candidates for DBS, but also for expanding the range of conditions for which DBS is used (Fig. 1).

The most recent World Society for Stereotactic and Functional Neurosurgery meeting, whose theme was "Emerging techniques and indications," held a premeeting workshop precisely on surgery for psychiatric disorders. The workshop made obvious the tensions between those who seem very optimistic about the possibilities and others stress the challenges ahead, including the complexities of targeting, as well as the fact that psychiatrists in general are unlikely to make referrals for this type of more invasive intervention. The workshop also highlighted the trend toward exploring new indications, as well as new techniques, in psychiatric neurosurgery. Similarly, in our data set, many papers discussed issues of innovation and/ or new indications for which DBS might be developed. While one-third of these papers also discussed COIs, explicit links between these issues were not made.

As new psychiatric indications are explored with the goal of reaching US FDA approval or expanding the market for current devices (e.g., not necessarily for patients whose condition is treatment refractory), the issue of COIs becomes more salient.

Moreover, while relatively few neurosurgeons and psychiatrists have been involved in these procedures, some of them are already involved in patents for brain regions ${ }^{45}$ and companies connected to neuromodulation. In this regard, disclosure to both research participants and patients becomes a key issue. A systematic review looking at the

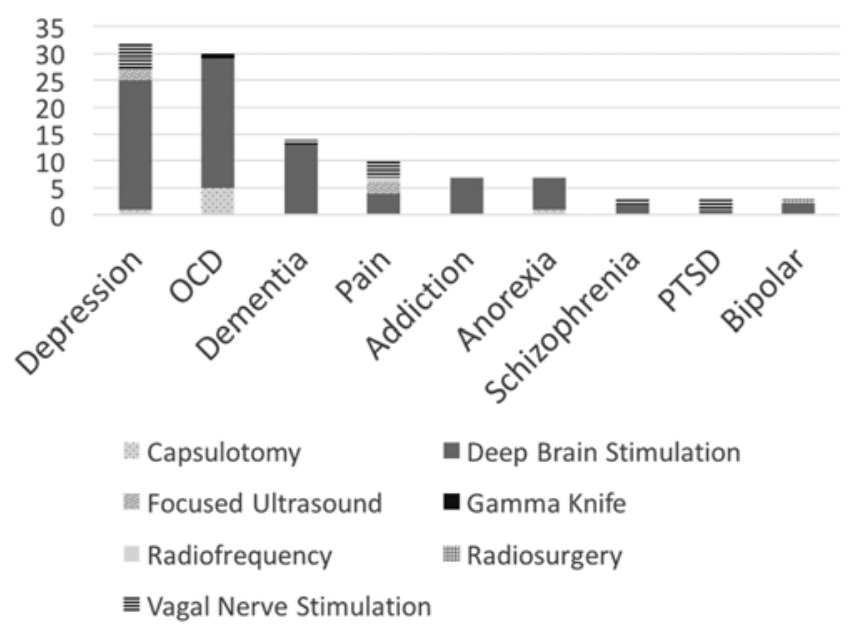

FIG. 1. Clinical trials for psychiatric neurosurgery. Data from clinicaltrials.gov, last updated August 2017. PTSD = post-traumatic stress disorder. 
impact of disclosing financial ties in research and clinical care found that in 6 of the 10 studies assessing the importance of disclosure, most patients and research participants believed financial ties should be disclosed, and that among the 7 studies assessing willingness to participate in research, approximately $25 \%$ of participants reported less willingness to participate after disclosure. ${ }^{31}$ The review was not specific to psychiatric treatments; thus, more research is needed in the specific case of psychiatric neurosurgery. In particular, patients who become candidates for a last-resort therapy might not properly consider the implications of potential COIs as a result of their desperation for a possible cure.

\section{Differences in the Type of Treatment}

A third reason for COIs being less frequently discussed with regard to neurosurgical interventions may be the differences in the nature of the treatments themselves. Patients may continue to take - and to pay for - a medication (or multiple medications) for years. Neurosurgical treatments, for example, require an initial higher cost and an invasive procedure, compared with pharmacological treatments. Yet patients do not continue to pay for the devices until batteries or hardware need to be replaced. This may change, however, if the quest for more market share leads some medical device companies to come up with schemes in which certain add-ons, software updates, or licensing fees and ongoing maintenance of the devices create extra charges on a more continuous basis.

While discussion of COIs and industry involvement in our neurosurgery data set focused primarily on DBS, there have already been cases of other medical devices entangled in COIs. A 2006 case involved an article reviewing the efficacy and safety of vagus nerve stimulation as a treatment for depression. ${ }^{36}$ None of the prominent academic psychiatrists who authored the paper, including Charles Nemeroff, who was the editor of the journal in which the article was published and the principal author of the paper, disclosed their financial ties to Cyberonics, the company making the implanted device.

\section{Differences in the Relationships Between Industry and Professionals}

Another key difference is the professionals involved. In the case of pharmaceuticals psychiatrists are often involved, whereas in the case of neurodevices neurosurgeons are involved. Another difference is the influence of industry on clinical trial design and results. COIs are well recognized in research on pharmaceuticals. Industrysponsored trials are more likely to show results that favor the sponsor's drug. ${ }^{4,30}$ Moreover, clinicians who participate as investigators in industry-sponsored studies face conflicts arising from their dual roles as clinician and as investigator. As investigators, they often have a financial incentive to enroll patients, ${ }^{44,47}$ because industry sponsors pay for the successful recruitment and enrollment of study participants. There is also evidence that these commercial sponsorships have an impact on the prescribing practices of physicians.

In the case of medical devices, there is also a close relationship between clinicians and industry, although the details of the relationship differ in important ways from the pharmaceutical case. For one thing, neurosurgeons, instead of being contractors for a trial of a drug that "belongs" to an industry sponsor, might hold patents related to a neurosurgical device, have shares in, or be on the board of directors of a medical device company. In addition, in some cases researchers depend on industry lending them the equipment to conduct studies. As Fins and colleagues noted,

[o]nly industry can practically design, or readily provide existing devices for use in clinical trials. While university engineers might design early prototypes, collaboration with an existing device maker - or significant venture capitalization to engineer a start-up venture-is necessary to meet stringent FDA investigational device exemption (IDE) applications which requires the achievement of a high level of design, manufacture, and oversight. ${ }^{19}$

These constraints on researchers make it necessary to collaborate with industry to do research.

Another important difference, both in our data set ${ }^{13,17}$ and in the broader discussion of COIs, ${ }^{19,20}$ is the more extensive discussion of the Bayh-Dole Act and patents for medical devices compared with pharmaceuticals. This seems to be related to the stagnation in terms of developing successful pharmacological drugs, and instead focused on innovation and patents that come from developing new neurodevices.

There are also potentially important differences in the relationships clinicians have with representatives of pharmaceutical companies and those of device manufacturers. It is well recognized that pharmaceutical sales representatives may influence prescribing practices through their relationships with prescribers. It is also recognized that physicians themselves may not fully appreciate the extent of this influence, although empirical studies show that such an influence does occur. ${ }^{26}$ However, these sales representatives are not present when physicians are interacting with their patients. By contrast, in the medical device industry, clinicians are not only "educated" about the latest advances in the industry but are constantly exposed to the representatives, who are present in each of the surgeries and play a key role in helping with programming and setting the device. While it is not clear from our exposure to the literature that this will be the case in terms of investigational use, it seems plausible considering that industry would not provide existing devices for clinical trials otherwise.

Yet, even when the interactions with industry are closer in the medical device industry arena, the interactions with the pharmaceutical industry are more wide reaching. This explains, in part, why a great deal of the discussion regarding COIs involves the pharmaceutical industry and not so much the medical device industry.

Another difference in terms of industry and marketing practices is the heavy, and oftentimes DTC, advertising pharmaceutical companies engage in. ${ }^{7,11,16,34,51}$ Until recently, medical devices have not engaged so actively in the practice of DTC advertising to patients, but that is changing as medical devices aim to increase their market share. Although outside the scope of our data set, a clear example of this is the appearance of transcranial magnetic stimulation, a medical device recently approved by the FDA for depression, on The Dr. Oz Show..$^{12}$ 


\section{Conflicts of Interest: (Near) Monopoly Held by Device Manufacturers}

The extent of competition between different companies is another big difference between pharmaceuticals and neurodevices. In the case of pharmaceuticals, there are various companies that market similar products, including, for older medications, generic drugs. However, in the case of neurostimulators, Medtronic is the world's largest and most prominent manufacturer of DBS devices, and until recently it was the only company with a commercially available DBS system. Although Medtronic continues to dominate both commercially and in terms of research worldwide, St. Jude and Boston Scientific have had ongoing research and are approved in Europe for Parkinson disease, essential tremor, and OCD, and are currently active in clinical trials for psychiatric DBS. Given the stilllimited competition in the psychiatric neurosurgery market, the tight connections between these companies and the research being conducted deserves further scrutiny. ${ }^{13}$

Considering all these points, we see COIs as a neglected issue in the discussion of ethics concerns regarding medical devices in psychiatry. As developments continue, more research will be needed to establish whether or not the topic is better addressed, to draw on lessons learned from the discussion regarding the pharmaceutical industry, and to develop better approaches to address those areas that are unique to the medical device industry in terms of COIs.

\section{Conclusions}

There are several areas, both regarding pharmaceutical interventions and medical devices, where COIs and relationships with industry overlap. That is why some recommendations can apply to research results sponsored or supported by pharmaceutical, medical device, or biotechnology companies. ${ }^{3}$ However, there are also substantial differences, such as the type of relationships found between pharmaceutical and medical device representatives. Overall, COIs involving medical devices have been inadequately analyzed, and standards for assessing and managing these COIs still need to be developed. Proper management is key to ensure transparency in research design and publication of results, to maintain trust both between the public and researchers and between clinicians and patients, and to sustain an evidence-based approach to inquiry and treatment that ensures the protection of research participants. The fact that little has been written about COIs in the psychiatric medical device industry does not make the issues less problematic than those related to pharmaceuticals.

\section{Acknowledgments}

We thank the anonymous reviewers whose insightful comments helped improving this manuscript. This study was supported by Science and Society at State (S3) at Michigan State University.

\section{References}

1. Ahmer S: Conflict of interest in psychiatry. Psychiatr Bull 29:302-304, 2005

2. Ancker JS, Flanagin A: A comparison of conflict of interest policies at peer-reviewed journals in different scientific disciplines. Sci Eng Ethics 13:147-157, 2007
3. Battisti WP, Wager E, Baltzer L, Bridges D, Cairns A, Carswell CI, et al: Good publication practice for communicating company-sponsored medical research: GPP3. Ann Intern Med 163:461-464, 2015

4. Bekelman JE, Li Y, Gross CP: Scope and impact of financial conflicts of interest in biomedical research: a systematic review. JAMA 289:454-465, 2003

5. Braun V, Clarke V: Using thematic analysis in psychology. Qual Res Psychol 3:77-101, 2006

6. Breggin PR: Psychopharmacology and human values. J Humanist Psychol 43:34-49, 2003

7. Cohan JA: Psychiatric ethics and emerging issues of psychopharmacology in the treatment of depression. J Contemp Health Law Policy 20:115-172, 2003

8. Cosgrove L, Bursztajn HJ, Krimsky S, Anaya M, Walker J: Conflicts of interest and disclosure in the American Psychiatric Association's Clinical Practice Guidelines. Psychother Psychosom 78:228-232, 2009

9. Cosgrove L, Krimsky S, Vijayaraghavan M, Schneider L: Financial ties between DSM-IV panel members and the pharmaceutical industry. Psychother Psychosom 75:154-160, 2006

10. Cosgrove L, Vannoy S, Mintzes B, Shaughnessy AF: Under the influence: the interplay among industry, publishing, and drug regulation. Account Res 23:257-279, 2016

11. Das A: Pharmaceutical industry and the market: The case of Prozac and other antidepressants. Asian J Psychiatr 4:1418,2011

12. The Dr. Oz Show: Transcranial magnetic stimulation: a cure for depression? Pt 2. March 14, 2012. (https://www. doctoroz.com/episode/5-controversial-solutions-your-biggestcomplaints?video_id=1848034860001) [Accessed June 14, 2018]

13. Erickson-Davis C: Ethical concerns regarding commercialization of deep brain stimulation for obsessive compulsive disorder. Bioethics 26:440-446, 2012

14. Fava GA: Conflict of interest in psychopharmacology: can Dr. Jekyll still control Mr. Hyde? Psychother Psychosom 73:1-4, 2004

15. Fava GA: The decline of pharmaceutical psychiatry and the increasing role of psychological medicine. Psychother Psychosom 78:220-227, 2009

16. Fava GA: The intellectual crisis of psychiatric research. Psychother Psychosom 75:202-208, 2006

17. Fins JJ, Mayberg HS, Nuttin B, Kubu CS, Galert T, Sturm V, et al: Misuse of the FDA's humanitarian device exemption in deep brain stimulation for obsessive-compulsive disorder. Health Aff (Millwood) 30:302-311, 2011

18. Fins JJ, Rezai AR, Greenberg BD: Psychosurgery: avoiding an ethical redux while advancing a therapeutic future. Neurosurgery 59:713-716, 2006

19. Fins JJ, Schiff ND: Conflicts of interest in deep brain stimulation research and the ethics of transparency. J Clin Ethics 21:125-132, 2010

20. Fins JJ, Schlaepfer TE, Nuttin B, Kubu CS, Galert T, Sturm $\mathrm{V}$, et al: Ethical guidance for the management of conflicts of interest for researchers, engineers and clinicians engaged in the development of therapeutic deep brain stimulation. $\mathbf{J}$ Neural Eng 8:033001, 2011

21. Ford PJ: Vulnerable brains: research ethics and neurosurgical patients. J Law Med Ethics 37:73-82, 2009

22. Frank E, Novick DM, Kupfer DJ: Beyond the question of placebo controls: ethical issues in psychopharmacological drug studies. Psychopharmacology (Berl) 171:19-26, 2003

23. Geppert CMA: Medical education and the pharmaceutical industry: a review of ethical guidelines and their implications for psychiatric training. Acad Psychiatry 31:32-39, 2007

24. Ghaemi SN, Goodwin FK: The ethics of clinical innovation in psychopharmacology: challenging traditional bioethics. Philos Ethics Humanit Med 2:26, 2007 
25. Gutheil TG: Reflections on ethical issues in psychopharmacology: an American perspective. Int J Law Psychiatry 35:387-391, 2012

26. Kirmayer LJ, Raikhel E: From Amrita to substance D: psychopharmacology, political economy, and technologies of the self. Transcult Psychiatry 46:5-15, 2009

27. Kölch M, Ludolph AG, Plener PL, Fangerau H, Vitiello B, Fegert JM: Safeguarding children's rights in psychopharmacological research: ethical and legal issues. Curr Pharm Des 16:2398-2406, 2010

28. Krimsky S, Rothenberg LS: Conflict of interest policies in science and medical journals: editorial practices and author disclosures. Sci Eng Ethics 7:205-218, 2001

29. Kristal JH: Commentary: first, do no harm. Then, do some good: ethics and human experimental psychopharmacology. Isr J Psychiatry Relat Sci 39:89-91, 2002

30. Lexchin J, Bero LA, Djulbegovic B, Clark O: Pharmaceutical industry sponsorship and research outcome and quality: systematic review. BMJ 326:1167-1170, 2003

31. Licurse A, Barber E, Joffe S, Gross C: The impact of disclosing financial ties in research and clinical care: a systematic review. Arch Intern Med 170:675-682, 2010

32. Mack N, Woodsong C, MacQueen KM, Guest G, Namey E: Qualitative Research Methods: A Data Collector's Field Guide. Durham, NC: Family Health International, 2006

33. Mayberg HS, Lozano AM, Voon V, McNeely HE, Seminowicz D, Hamani C, et al: Deep brain stimulation for treatmentresistant depression. Neuron 45:651-660, 2005

34. McHenry L: Ethical issues in psychopharmacology. J Med Ethics 32:405-410, 2006

35. Müller-Oerlinghausen B: Ethical problems in clinical psychopharmacology. Int J Clin Pharmacol Biopharm 16:443-450, 1978

36. Nemeroff CB, Mayberg HS, Krahl SE, McNamara J, Frazer A, Henry TR, et al: VNS therapy in treatment-resistant depression: clinical evidence and putative neurobiological mechanisms. Neuropsychopharmacology 31:1345-1355, 2006

37. Nuttin B, Cosyns P, Demeulemeester H, Gybels J, Meyerson B: Electrical stimulation in anterior limbs of internal capsules in patients with obsessive-compulsive disorder. Lancet 354:1526, 1999

38. Nuttin B, Gybels J, Cosyns P, Gabriels L, Meyerson B, Andréewitch S, et al: Deep brain stimulation for psychiatric disorders. Neurosurgery 51:519, 2002

39. Nuttin B, Wu H, Mayberg H, Hariz M, Gabriëls L, Galert T, et al: Consensus on guidelines for stereotactic neurosurgery for psychiatric disorders. J Neurol Neurosurg Psychiatry 85:1003-1008, 2014

40. Perlis RH, Perlis CS, Wu Y, Hwang C, Joseph M, Nierenberg AA: Industry sponsorship and financial conflict of interest in the reporting of clinical trials in psychiatry. Am J Psychiatry 162:1957-1960, 2005

41. Relman AS: Dealing with conflicts of interest. N Engl J Med 310:1182-1183, 1984

42. Roberts LW, Jain S: Ethical issues in psychopharmacology: considerations for clinical practice. Psychiatric Times. May 31, 2011. (https://pro.psychcentral.com/ethical-issues-inpsychopharmacology-considerations-for-clinical-practice/) [Accessed June 14, 2018]

43. Rogers WA, Mansfield PR, Braunack-Mayer AJ, Jureidini JN: The ethics of pharmaceutical industry relationships with medical students. Med J Aust 180:411-414, 2004

44. Rosenstein DL, Miller FG: Ethical considerations in psycho- pharmacological research involving decisionally impaired subjects. Psychopharmacology (Berl) 171:92-97, 2003

45. Roskams-Edris D, Anderson-Redick S, Kiss ZH, Illes J: Situating brain regions among patent rights and moral risks. Nat Biotechnol 35:119-121, 2017

46. Saldana J: An intro to codes and coding, in: The Coding Manual for Qualitative Researchers. London: SAGE, 2008, pp 1-31

47. Scahill L, Solanto M, McGuire J: The science and ethics of placebo in pediatric psychopharmacology. Ethics Behav 18:266-285, 2008

48. Schermer M: Ethical issues in deep brain stimulation. Front Integr Nuerosci 5:17, 2011

49. Slingsby BT: The Prozac boom and its placebogenic counterpart-a culturally fashioned phenomenon. Med Sci Monit 8:CR389-CR393, 2002

50. Sperry L, Prosen H: Contemporary ethical dilemmas in psychotherapy: cosmetic psychopharmacology and managed care. Am J Psychother 52:54-63, 1998

51. Strous RD: Ethical considerations in clinical training, care and research in psychopharmacology. Int J Neuropsychopharmacol 14:413-424, 2011

52. Svenaeus F: Psychopharmacology and the self: an introduction to the theme. Med Health Care Philos 10:115-117, 2007

53. Tan JOA, Koelch M: The ethics of psychopharmacological research in legal minors. Child Adolesc Psychiatry Ment Health 2:39, 2008

54. Thompson DF: Understanding financial conflicts of interest. N Engl J Med 329:573-576, 1993

55. Touwen DP, Engberts DP: Those famous red pills-deliberations and hesitations. Ethics of placebo use in therapeutic and research settings. Eur Neuropsychopharmacol 22:775-781, 2012

56. Valenstein ES: Great and Desperate Cures: The Rise and Decline of Psychosurgery and Other Radical Treatments for Mental Illness. New York: Basic Books, 1986

57. Varley CK, Jibson MD, McCarthy M, Benjamin S: A survey of the interactions between psychiatry residency programs and the pharmaceutical industry. Acad Psychiatry 29:4046, 2005

58. Wazana A: Physicians and the pharmaceutical industry: is a gift ever just a gift? JAMA 283:373-380, 2000

\section{Disclosures}

The authors report no conflict of interest concerning the materials or methods used in this study or the findings specified in this paper.

\section{Author Contributions}

Conception and design: Cabrera. Acquisition of data: Cabrera, McKenzie. Analysis and interpretation of data: Cabrera, McKenzie, Bluhm. Drafting the article: Bluhm. Critically revising the article: all authors. Reviewed submitted version of manuscript: Cabrera, Boyce, Bluhm. Approved the final version of the manuscript on behalf of all authors: Cabrera. Statistical analysis: Cabrera. Administrative/technical/material support: Cabrera. Study supervision: Bluhm.

\section{Correspondence}

Laura Y. Cabrera: Michigan State University, East Lansing, MI. laura.cabrera@hc.msu.edu. 